\title{
JUURNAL.RU
}

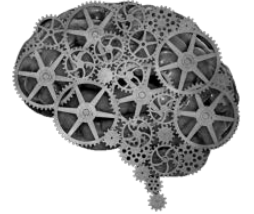

COMPANY GROUP "INTELLEKT"

Темирбулатов К.Р., Хальметов А.А. Саратовский государственный аграрный университет им. Н.И. Вавилова

Саратов, Россия

doi: 10.18411/lj2016-5-5-03

\section{Способ защиты зданий и сооружений от разрушения при взрыве газопаровоздушной смеси}

Взрывы вызывают не только прямые материальные убытки, связанные с разрушением строительных конструкций, технологического оборудования, но и не исключают травматизм и гибель людей в результате их поражения в основном обрушающимися конструкциями. Проблема защиты людей, оборудования и зданий строительными методами от взрывов горючих смесей внутри помещений имеет не только большое экономическое значение, но и социальное.

Взрывозащита зданий решается в основном по двум направлениям. Основным направлением является исключение возможности возникновения взрыва. В тех случаях когда это сделать с достаточной степенью надежности не представляется возможным, предусматривается защита зданий и сооружений строительными методами - применением легкосбрасываемых конструкций в зданиях с целью снижения нагрузок, действующих на ограждающие конструкции.[2]

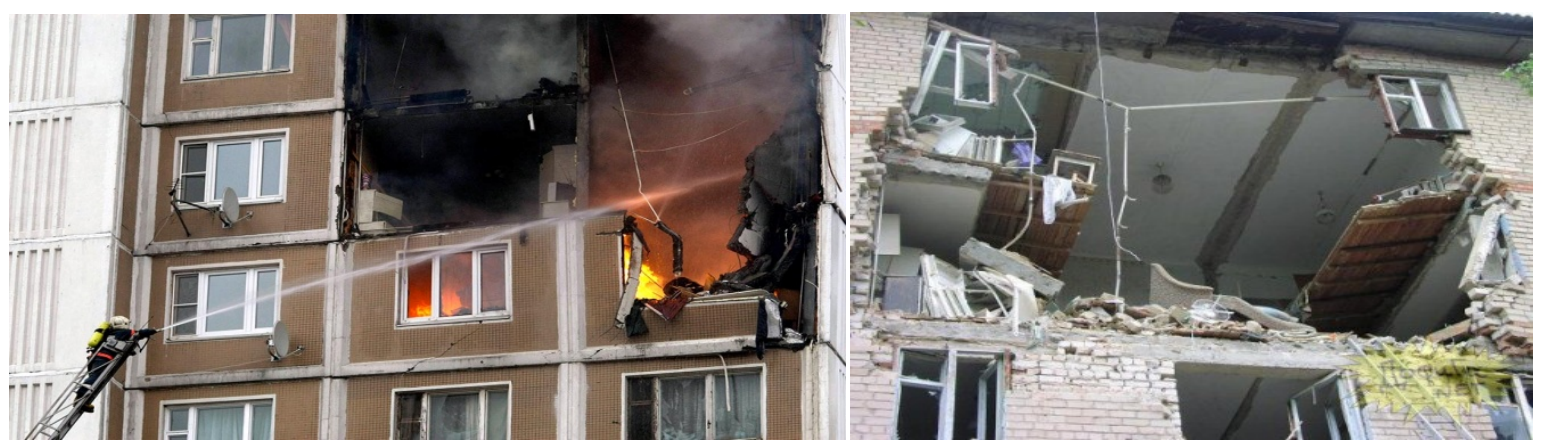

Рисунок 1 - Последствия взрыва газа в жилых домах 
Окна как один из видов легкосбрасываемыех конструкций.

Современные пластиковые окна отличные, не пропускают ни влагу, ни звук. Но вот произошла утечка газа на кухне, следом - взрыв, фронт горения бежит, поднимая свое давление. Надо всю энергию взрыва выпустить через проемы, через окна на улицу. Там эта волна уже не так страшна. Но пластиковые стеклопакеты “стоят насмерть”, распахиваться не хотят. Кухня превращается в изолированную от внешнего пространства камеру. Взрыв в столь ограниченном объеме вырывает из стены целую панель, после чего конструкция может сложиться как карточный домик (рис.1).

Одной из основных причин значительных разрушений жилых зданий при аварийных взрывах является установка в помещениях с газовыми приборами усиленных вариантов остекления, что противоречит нормам взрывозащиты. Если установлены обычные деревянные оконные рамы, то газовым хлопком их просто вышибет, если новые пластиковые окна - то вся энергия взрыва пойдет на строительные конструкции.При аварийных взрывах окна, оборудованные таким остеклением, не выполняют роль предохранительных конструкций, что приводит к резкому повышению взрывного давления.

В качестве защиты от внутренних дефлаграционных взрывов в настоящее время применяется одинарное и двойное остекление или так называемые легкосбрасываемые конструкции (ЛСК) - стеновые и навесные панели и другие предохранительные конструкции. Все они работают по схожему принципу: вскрытие происходит при достижении определенного значения давления внутри помещения, т.е. давления вскрытия.[1]

До сего времени существуют три относительно надежных способа размыкания замкнутого объема помещения:

1. Остекление помещения выполняется стеклом не толще 3 мм в один слой. Такое остекление в начальной стадии развития дефлаграции разрушается, открывая выход газам в окружающее пространство. Это - самый простой и дешевый в исполнении, но и самый опасный и дорогой в эксплуатации. При 
разрушении стекла люди, находящиеся на улице, будут поражены его осколками. Попытка сделать стекло безосколочным за счет установки ударопрочных пленок повышает его прочность и делает неразрушимым вплоть до давления 25-35 кПа. Кроме того, однослойное остекление тонким стеклом приведет к большому перерасходу энергии на отопление, а с другой стороны, сделает остекление легкоуязвимым для малоэнергетических воздействий как снаружи, так и изнутри помещения.

2. При нормальном современном остеклении, в т.ч. и при заполнении светопроемов стеклопакетами, многослойными ламинированными стеклами, закаленными, армированными стеклами, в стенах или крышах зданий устраиваются проемы заданного размера и заданной суммарной площади, заполненных легковскрываемой конструкцией требуемой прочности, которая открывается при заданном избыточном давлении, использующие конструкцию рама в раме. По мере повышения давления всего на 0,2 атм. благодаря специальному предохранительному устройству окно распахивается. Чем и обеспечивается сброс давления в атмосферу (рис. 2).

3. Существующие светопроемы с установленными в них оконными системами любой конструкции снабжаются специальными устройствами, открывающими окна при повышении давления в помещении до заданной величины. В отличие от первых двух способов давление срабатывания системы может задаваться в широких пределах для исключения случайного срабатывания (рис. 3) [3].

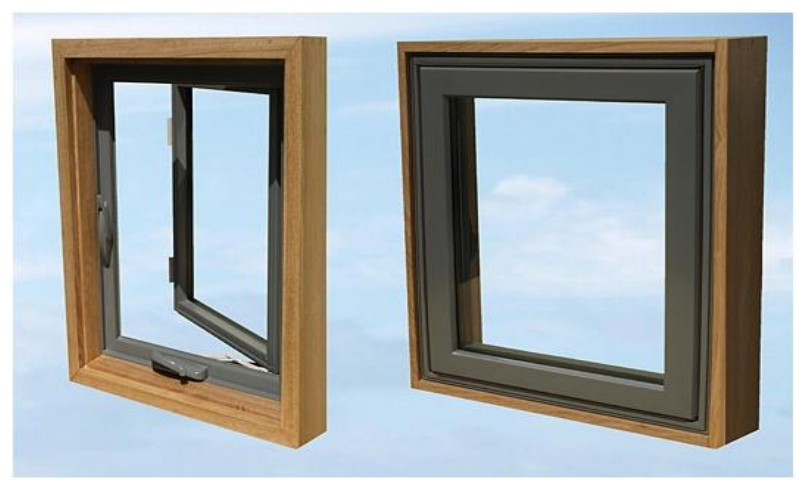

Рисунок 2 - Окно с дополнительной рамой внутри 
Устройство, представленное на чертеже, состоит из внутренней встраиваемой в оконную конструкцию створки 1, открывающейся наружу, для сброса в атмосферу газопаровоздушной смеси и продуктов сгорания во время взрыва, элемента, реагирующего на повышение давления внутри помещения мембранного датчика давления 2 определенного диаметра, жестко связанного с помощью кронштейнов и соединительных элементов $\mathrm{c}$ запирающим механизмом 3 на встраиваемой створке 1 с помощью штока 4, перемещающегося в направляющей втулке 5.Створка 1 крепится петлями к раме 6 , открывающейся внутрь помещения по условиям безопасности, и в рабочем положении закручивает торсионы 7, стержни которых одновременно являются крепежными пальцами для петель 8 внутренней створки. Торсионы 7 представляют собой пакет из 2-4 пластин из специальной высокопрочной стали. Один конец пакета жестко закреплен в стальной обойме, которая вмонтирована в раму окна, а второй конец пакета закреплен в гильзе, вмонтированной в открывающуюся створку окна, и выполняет роль шарнира [4].

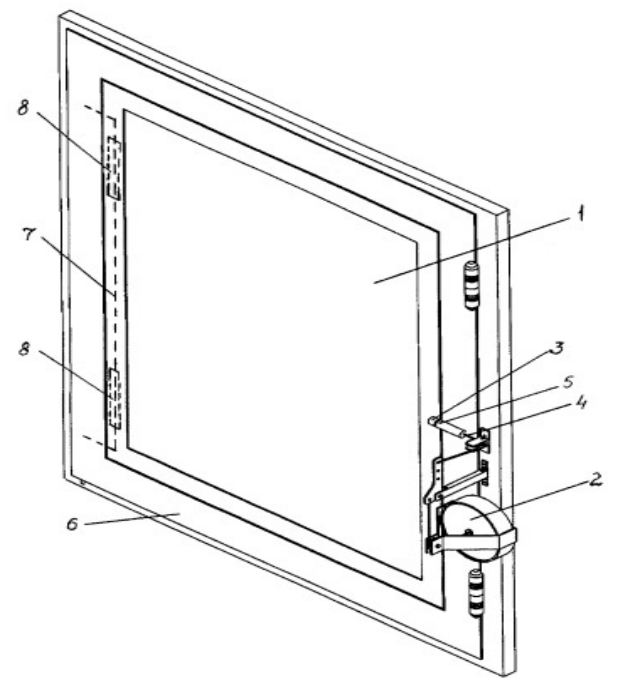

Рисунок 3 - Окно с системой измерения давления и открывания

Наиболее выгодными окнами считаются те, что используют систему рама в раме (рис.2), так как из-за относительной простоты конструкции цена не высока в 1.5 раза больше чем обычный стеклопакет и обслуживание так же не составляет труда по сравнению с окнами со специальными датчиками (рис. 3). В этой конструкции из-за сложности технических решений, присутствует 
множество недостатков, таких как цена, сложность монтажа обслуживания. Так же из-за постоянной необходимости к электроисточнику повышается риск несработки системы в нужный момент. Поэтому оптимальным вариантом является окна рама в раме.

\section{Литература:}

1. Водяник В.И. Горение и взрыв газов // Безопасность труда в промышленности. - 2005. - № 1. - С. 57-59.

2. http://otipb.ucoz.ru/publ/2-1-0-108 - как противостоять взрывам газа.

3. http://www.mk.ru/science/2011/02/17/566598-moskovskie-vzryivniki-sidyatv-podpole.html - Главного управления гражданской защиты Москвы.

4. Патент РФ №2301312 Способ защиты зданий и сооружений от разрушения при взрыве газопаровоздушной смеси и устройство для обеспечения взрывобезопасности помещений 2007 г. 